\title{
Movement Characteristics of Processions
}

\author{
Petros Polichronidis and Michael Schreckenberg \\ Physik von Transport und Verkehr/Universität Duisburg-Essen \\ Lotharstr. 1, 47057 Duisburg, Germany \\ petros.polichronidis@uni-due.de; michael.schreckenberg@uni-due.de
}

\begin{abstract}
Processions are a scientifically not much investigated traffic system. Recent studies found that the first participant in the Cologne Rose Monday parade has a remarkable higher travel time than the last participant. The velocity profiles of the participants are explained by the constant moving vehicle driving ahead of the parade leaving the pathway and partly due to a spatial contraction of the parade during the procession. This contribution compares the traffic kinematics of the Cologne Rose Monday parade in Germany with other processions (Schuetzenausmarsch Hanover 2017, Niederrheinischer Kinderkarnevalsumzug 2018). The kinematics of these processions were analysed based on GPS data from participants. Their kinematics differ from those of the Cologne Rose Monday parade. In general, the observations depend on the size of a procession, the length of its pathway, the composition of the procession and especially on the catching up behaviour, of the participants, when gaps occur in front of them. Furthermore, we examine the influence of the pathway on the traffic flow. This can be used to choose a parade's pathway avoiding flow reducing infrastructure characteristics like traffic area transitions, narrow curves etc. In summary, this work extends the understanding of the kinematics of processions. It can serve as a basis upon which the parade's movement can be predicted and so the duration of such events can be estimated better.
\end{abstract}

Keywords: Transportation, GPS data, random processes, parades, processions

\section{Introduction}

Processions are a subject of little attention in the literature so far. In particular, there is, to our knowledge, no analysis and modeling based on empirical data of the kinematics of processions. One of the few works dealing with traffic at street parades or carnivals has been published by M. Batty, J. DeSyllas and E. Duxbury [1]. They describe the impact of the route of the parade and the entire event on the surrounding traffic. In particular, simulations are used to check how traffic can be influenced by a modified parade route. In this context, we recently published a study in which a detailed data analysis of the kinematics of the Cologne Rose Monday procession is presented [2]. We developed a cellular automaton based parade group model for processions as a modified Nagel-Schreckenberg model. The statistical analysis of the kinematics of the Cologne Rose Monday procession carried out on the basis of provided GPS data from 2014, brought out characteristics of the movement that can be qualitatively reproduced by the parade group model.

An essential observation is that the foremost participants in this procession move along the pathway much faster than those at the lead. This is particularly interesting as one would normally expect the opposite, since it is a matter of a traffic system that is predominantly influenced by stop-and-go or congested traffic. This is exemplarily shown for the data set from 2014 in figure 1a. This phenomenon can be partly explained by the constantly moving leader driving ahead of the parade, leaving the pathway. Figure $1 \mathrm{~b}$ illustrates the velocity of the whole processions averaged over time. The red line indicates the time point at which the leader of the parade leaves the pathway at the end. After its egress, a considerable increase of the velocity is observed. The quantitatively unidentified proportion of the velocity increase is due to the spatial contraction of the entire parade. The distances between the individual participants, with which they are deployed in the area in front of the path start, are not maintained during the parade. As a result, the passing by took about four hours at the end and about five hours at the beginning of the pathway in 2014 . 
In this contribution, we compare our earlier results with the kinematics of two other processions, the Marksmen's parade 2017 in Hanover and the Niederrheinischer Kinderkarnevalszug 2018 in DuisburgHamborn/Marxloh. At first, the methodology of the GPS measurement is described. Then an overview of general features of processions is given and afterwards the results of the data analysis are presented. Subchapter 4.1 describes the influence of the infrastructure on the dynamics of the Cologne Rose Monday parade from 2014. The velocity dependencies of the other mentioned parades are shown in subchapter 4.2.

a)

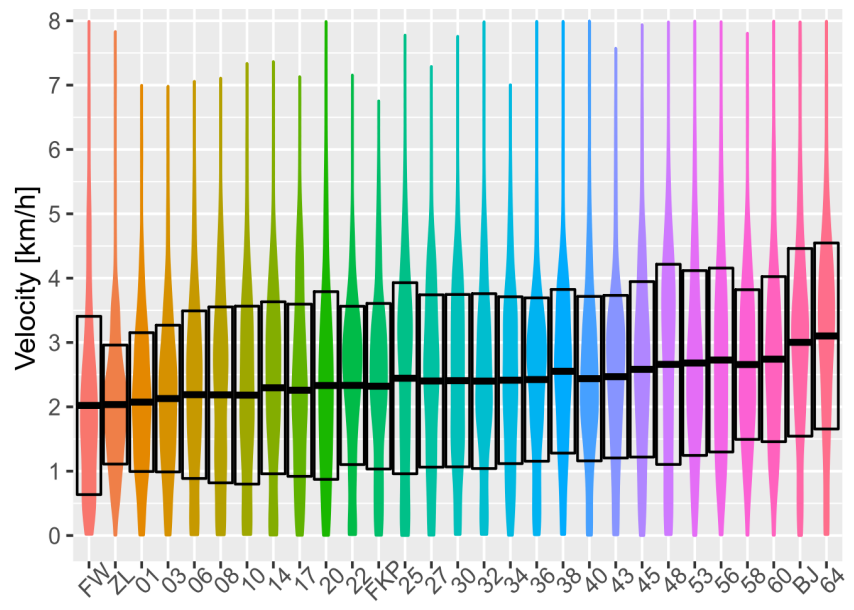

Parade group b)

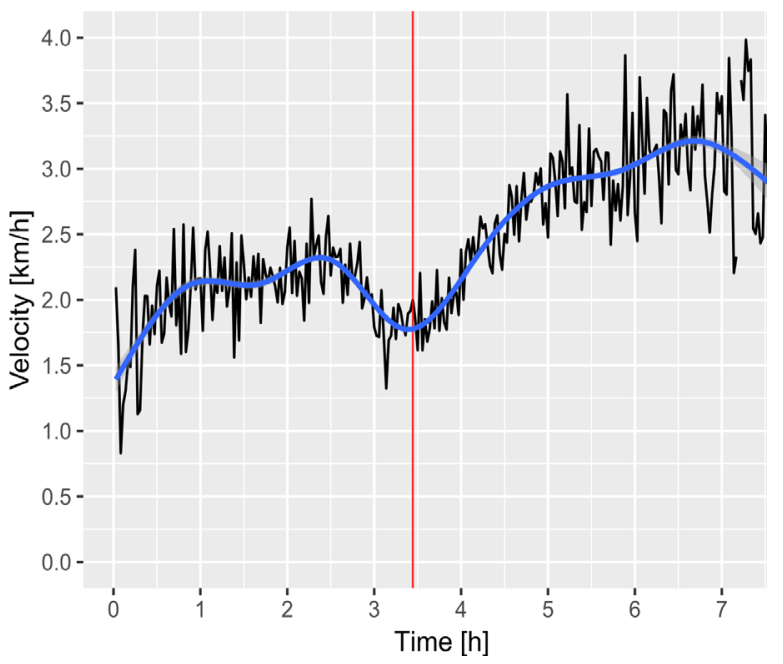

Fig. 1: a) Velocity distributions specifically colored for each GPS equipped parade group in the Cologne Rose Monday parade 2014. The boxes describe the standard deviation and the wide middle lines the mean values of the distributions. b) Velocity-time diagram: The black line represents the average velocity and the blue line an interpolated course. The width of the shaded area around the blue line corresponds to the quality of the interpolation. The red vertical line marks the time point at which the fire truck (leader) leaves the parade route. After this moment, the average velocity of the procession increases. [2]

\section{GPS-Measurement/Methodology}

The GPS Data required for the analysis of the traffic dynamics of the Cologne Rose Monday parade were provided by the Festkomitee Kölner Karneval von 1823 e.V. In 2014, 30 parade groups out of 65 were equipped with a GPS device so that the movement of the whole procession can be studied. The temporal resolution of this measurement was 30 seconds. For the collection of the traffic data of the Marksmen's Parade in Hanover and the Niederrheinischer Kinderkarnevalszug we used the GPS data logger Columbus $V-990$, logging the data with a temporal resolution of 1 second. The recording of the parade's movement was performed with 8 devices in equidistant placements in the procession.

In narrow streets with partly tall buildings, the accuracy of positioning has been reduced due to blocked or reflected GPS signals, as described in [3]. Due to the lateral inaccuracy of the GPS measurement, a map-matching was performed. Since the true position in the map should be known for the analysis of the GPS data, the map-matching algorithm is used to match the measured positions with a one-dimensional route in the road network of the city of Cologne, Hanover and Duisburg-Hamborn/Marxloh. The aim of these widely used map-matching algorithms is to determine coordinates of the recorded data corresponding to the actual positions of the GPS carrier most likely [4]. However, due to the transversal inaccuracy of the measurement, a change of the spatiotemporal order of the measuring points occurs. In addition, this order is disturbed by the orthogonal projection on narrow curves and at locations where the inaccuracy of the GPS measurement is bigger than the distance between two pathway sections. To filter only the data points with decent quality, an algorithm was developed that identifies the misprojected data points. 


\section{Characteristics of Processions}

The kinematics of processions exhibit characteristics that differ from common road traffic. In general, the traffic flow of a system can be distinguished between interrupted and uninterrupted flows. In the case of an uninterrupted flow, the kinematics depend mainly on the roadway characteristics and the interactions between vehicles or traffic participants. On the other hand, traffic control systems (e.g. traffic signals, etc.) characterize interrupted traffic flows. However, processions mostly take place on a onedimensional route and do not experience any kind of controlled flow interrupt. The movement dynamics are dominated by interactions of the participants with the infrastructure, visitors and the preceding participants. In the following, we will give an overview of the involved characteristics.

\subsection{Boundary conditions}

A procession can be classified regarding the kind of boundary condition. The major part exhibits open boundaries, which means that the parade's pathway has a start and a finish. Thus participants run the pathway down only once. In contrary, processions with periodic boundary conditions let the participants run the pathway several times down along a full circle. The weakest or slowest participant dominates the kinematics in a heterogeneous composited procession with periodic boundaries. Due to lack of data for processions with periodic boundaries, we study in the course of this contribution only processions with open boundary conditions.

\subsection{Leader of a procession}

Processions are commonly led by a participant who prescribes a specific velocity for the following parade. In the case of the Cologne Rose Monday parade the leader is a fire truck, whose gear ratio is capable to drive at three different, low velocities. The travel times of this truck have been measured on a test track of $1000 \mathrm{~m}$ and the velocities were calculated. The fire truck can drive in first gear at $1.428 \mathrm{~km} / \mathrm{h}$, in second gear at $2.068 \mathrm{~km} / \mathrm{h}$ and in the third gear at $2.307 \mathrm{~km} / \mathrm{h}$. The leader in the Niederrheinischer Kinderkarnevalsumzug is likewise a specially adjusted carnival float capable to constantly prescribe a low velocity. The Marksmen's parade in Hanover whereas is headed by a public person by feet. This cannot hold a constant velocity by its very nature is contrary to an idling mixture supply. The velocity behaviour of the parade's leader is therefore either constant or varying and yet a variation of the velocity prescription can be reasoned or inherently chaotic.

\subsection{Pathway, composition}

The infrastructure of a parade essentially influences the dynamics of the procession. There are sections along the parade's path where participants have to adjust their speed for different reasons. Such places are exemplarily due to the festive activities along the pathway. Those are where the grandstands, party trucks, areas with high visitor numbers are located and a strong parader-visitor-interaction is observed. The interludes of the dancing groups are normally performed in front of the visitors, which gather increasingly on the grandstands and the load platforms of the trucks. There are also sections where the float drivers need to be extra careful because they come very close to buildings and sections, where the pathway width is only a little wider than the widest float. In the Cologne Carnival procession in front of the Hotel Mondial, there is a cobblestone paved road with a slope. The equestrian coaches cannot drive this part of the route, as long as the preceding group is still on this section. They wait at the intersection until they can pass through the section without interruption. A stop on the slope carries the risk of overloading the horses. There are several such sections on the path, which act as flow-reducing bottlenecks.

Further important properties of a procession are the length of the parade and its pathway. The parade route length of the Cologne Rose Monday parade is $7.6 \mathrm{~km}$ [5], of the Marksmen's parade in Hanover $3 \mathrm{~km}$ and the Niederrheinischer Kinderkarnevalszug in Duisburg-Hamborn $3.2 \mathrm{~km}$ long. If the pathway is shorter than the parade itself, the first participants already pass the end of the route, while the last participants are still waiting for their entry at the beginning of the path. Due to the absence of the velocity-prescribing leader, the adopted velocities mainly depend on the parade's composition and the paraders' behaviour.. 
Processions partially differ considerably in their composition (see table 1). In the case of demonstrations or protests and Corpus Christi processions, all participants move by foot, whereas in the case of the Niederrheinischer Kinderkarnevalszug, almost only motorized participants are taking part along with a few music and foot groups.

Table 1: Composition of the studied processions. The data for the Marksmen's parade and the Kinderkarnevalszug is based on observations from video recordings.

\begin{tabular}{|l||r|r|r|}
\hline \multicolumn{1}{|c||}{ Participants } & $\begin{array}{c}\text { Cologne Rose Monday } \\
\text { Parade 2014 [5] }\end{array}$ & $\begin{array}{c}\text { Marksmen's } \\
\text { parade Hanover } \\
\mathbf{2 0 1 7}\end{array}$ & $\begin{array}{c}\text { Niederrheinischer } \\
\text { Kinderkarnevalsumzug } \\
\mathbf{2 0 1 8}\end{array}$ \\
\hline \hline Persons in foot groups & 3276 & 5302 & 400 \\
\hline Persons in music groups & 3130 & 2828 & 125 \\
\hline Horses & 328 & 35 & 0 \\
\hline Coaches & 54 & 7 & 2 \\
\hline Cars & 67 & 16 & 22 \\
\hline Trucks/tractors & 85 & 17 & 0 \\
\hline
\end{tabular}

Essentially, the participants can be classified in terms of their acceleration and braking ability. Typically, pedestrians are assumed to be able to accelerate to their targeted speed instantaneously, as well as decelerate from it to $\mathrm{v}=0 \mathrm{~km} / \mathrm{h}$. While they are on the move, their velocity besides physiological factors (age, gender, size, fitness) is limited because of the leading participants. In comparison to this disordered movement of the groups on foot, the participants in the music corps keep a predetermined stepping frequency by the marching music. As a result, a music group moves along as a contiguous foot group in a correlated manner, without changing the gaps between the musicians significantly.

In order to be able to assess the dynamics of the procession as a whole, it is incessant to consider the behaviour of the individual participants and thus the composition of the parade. The types of processions discussed in this article take place on festive occasions, such as the Rheinische Carnival or Marksmen's parades in Germany. The behaviour of the participants in these processions differs and causes the kinematics of these procession types to differ.

While participants in the Cologne Rose Monday parade are encouraged not to allow gaps or to close them immediately, the participants in past-marches on Marksmen's parades as well as in military parades march orderly in lockstep or goose step through streets and squares. The marching music helps the effort to maintain the organized, steady and rhythmic walking forward. The correlated motion in a Marksmen's parade, as well as in military parades, mainly depends on the following details.

To start the move, the general gives the marching orders. Shortly thereafter, the music corps start to play the marching music and on the second beat, the first step is taken in the collective. The foot group starts and follows the rhythm of the commander. His group follows him in the cadence prescribed by him also against the rhythm of the music. Usually, in a Marksmen's parade, some foot groups follow before the next music corps follows. Ideally, the music groups are synchronized with the music. If a synchronization of the bands is not possible, subsequent bands are just beginning to play, when the preceding music group has finished their playing. To intercept deviations, a so-called Spiess runs alongside each foot group to maintain order and to correct the participants. This Spiess has a particular importance in the movement of Marksmen's parades He ensures that the gaps between the parade groups, between the individual foot and music groups and between the ranks of the individual participants in the groups are maintained. The formation in the groups is ordered by body size. By tending to take larger steps, the bigger persons run a little faster and usually have to be "reminded" to keep their distance more often. 


\section{Results}

\subsection{Influence of the pathway on the kinematics}

In this subchapter, the effect of the parade's pathway on the kinematics of the Cologne Rose Monday procession is described. The data is explored with respect to conspicuous route sections, where the procession adopts velocities above or below average velocities. For this purpose, the variance of velocity along the pathway is considered for all years. Since the parade route was not changed over the years for which data sets were provided, a correlated behaviour of the variances is observed. Therefore, the following figures give an exemplary overview of the distribution of obstructive sections along the pathway from 2014. The four dominant peaks in Fig. 2 are explained in table 2 in more detail.

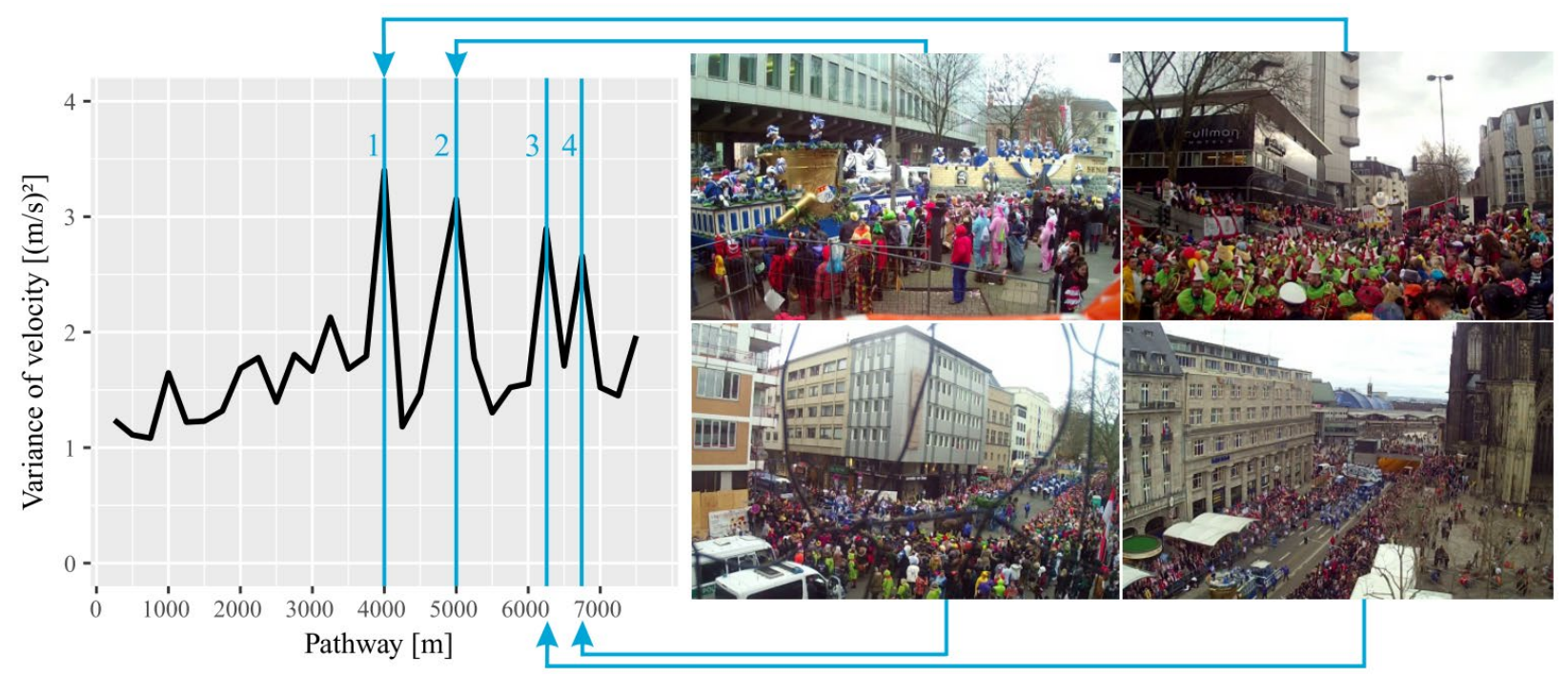

Fig. 2: Variance of the speed versus the travel path for the data set from 2014: The blue lines mark the maxima correlated for 2014 and 2016. The right pictures illustrate the corresponding local situation.

For the calculation of the variance, the path was divided into averaging intervals of $250 \mathrm{~m}$. Because of the functional rule of the variance, only conclusions about the modulus of change is possible. However, it is probable that the local maxima observed here are solely indicative of velocity drops. This is based on observations in video recordings and in the participation in the event itself, as well as on statements of the festive committee of the Cologne Carnival, who described these sections in advance as flow reducing. Table 2 briefly describes the locations represented by vertical lines in Figure 2. In addition to the numbering and position indication, the main cause of the obstacles in these areas is described.

Table 2: Position and description of the main flow reducing sections along the Cologne Rose Monday parade's pathway

\begin{tabular}{|c|c||l|}
\hline No. & Position [m] & \multicolumn{1}{c|}{ Description } \\
\hline \hline $\mathbf{1}$ & 4000 & $\begin{array}{l}\text { Due to the large number of stands and party trucks, the number of visitors is } \\
\text { particularly high. Since the path in this area is only demarcated from the visitors } \\
\text { by means of barrier tape, they crowd onto the path and narrow the pathway } \\
\text { width. In this state, the section acts like a bottleneck. The photo shows the parade } \\
\text { and the audience, a clear demarcation is not recognizable. }\end{array}$ \\
\hline
\end{tabular}




\begin{tabular}{|c|c||l|}
\hline 2 & $\begin{array}{l}\text { In this section, the route winds along some narrow curves through the area at the } \\
\text { Appellhofplatz and in front of the Vier-Scheiben-Haus. There are sections, where } \\
\text { the road width is not sufficient so that it is heaped up to form ramps on sidewalks. } \\
\text { In particular, float with excess length must be ranked very cautiously here. The } \\
\text { corresponding picture shows two large floats passing through the bottleneck. }\end{array}$ \\
\hline $\mathbf{3}$ & $6950 \begin{array}{l}\text { At the illustrated curve in the area of the street Am Hof, the route has a slope. On } \\
\text { this slope draft horses with carriages must not stop, because the starting is very } \\
\text { difficult for draft horses. Therefore, the carriages should wait at the curve until } \\
\text { the ascent or the next } 100 \mathrm{~m} \text { are free. In addition, the road is paved with } \\
\text { cobblestone, which is slippery in the rain. These features naturally lead to a } \\
\text { traffic jam. }\end{array}$ \\
\hline $\mathbf{T}$ & $\begin{array}{l}\text { The parade route leads along the Trankgasse to the main station forecourt. There, } \\
\text { it forms a traffic area transition from the street to traffic areas intended } \\
\text { exclusively for pedestrians. The high sidewalk (20 - 30 cm) is bridged by a ramp } \\
\text { and must be driven carefully by the drivers. }\end{array}$ \\
\hline
\end{tabular}

\subsection{Analysis of the velocities in the Marksmen's parade Hanover 2017 and the Niederrheinischer Kinderkarnevalszug 2018}

In this subchapter, the analysis of the kinematics of the Marksmen's parade 2017 in Hanover and the Niederrheinischer Kinderkarnevalsumzug 2017 in Duisburg-Hamborn is presented. Figure 3 illustrates the dependency of the averaged parade velocity against time. For this, the arithmetic average of all velocities was calculated over a time interval of 10 seconds. This course is shown in Figure 3 by the black curve.

a)

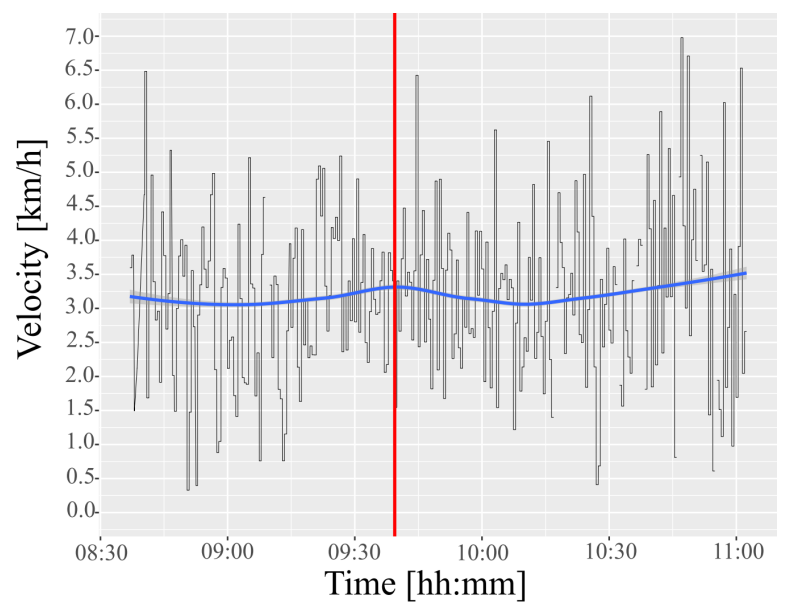

b)

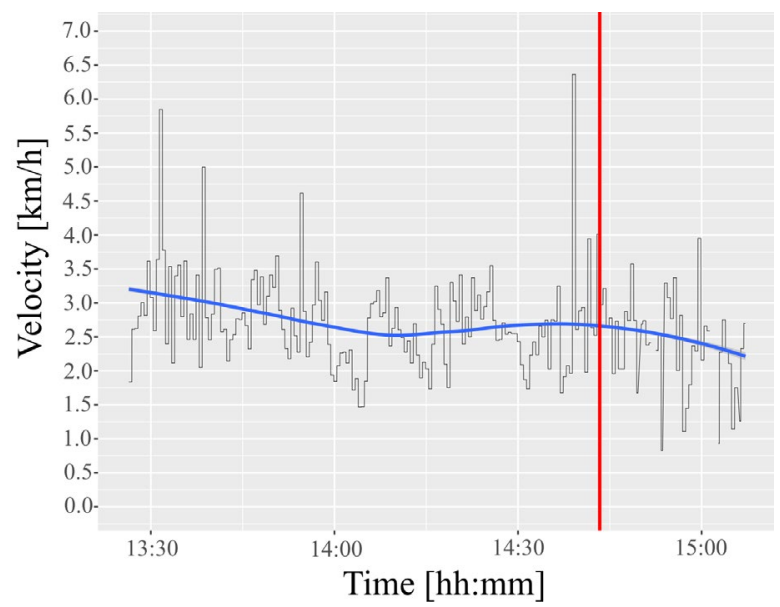

Fig. 3: Velocity-time diagram of the studied parades; a) Hanover Marksmen's parade 2017, b) Niederrheinischer Kinderkarnevalszug 2018: The black line represents the over a time interval of 10 seconds averaged velocity and the blue line an interpolated course. The red vertical line marks the time point at which the leader of the parade leaves the route. After this moment, the velocity increases in a) not considerably, in b), the velocity continues its decrease during the whole procession.

The blue, superimposed line shows an interpolation of the determined values and the associated gray, shaded area around the blue curve corresponds to the degree of accuracy of the interpolation. The red line, as in Figure 1b, corresponds to the time point at which the leader of the parade reaches the end of the pathway. Up to the outlet of the leader, the velocity is kept nearly constant. The pageant experiences up to this point, a minimal increase in velocity. After this time, the average speed of the parade decreases. Based on this illustration it can be asserted that the missing velocity prescribing leader causes no increase, but in 
fact a change in the velocity of the following. This is due to the effort of the participants to move in order and uniformly, rather to close up the ranks. This behaviour is indicative of arising gaps, which are indeed observed in video recordings of the parade.

Figure $3 \mathrm{~b}$ ) depicts a similar illustration to Figure 3 a). Due to the brevity of the procession (both temporal and spatial), the exit of the leader can be observed relatively late. The course of the average speed as a function of time shows a monotonous decrease towards later times. In particular, no increase in velocity is observed after the leading participant has left the pathway. Rather, the declining behaviour continues. It is noteworthy that the parade comes to a standstill at approximately 14:00 h. The velocity breakdowns within the last half hour are due to arising congestion in the dissolution area, after the end of the path. That at the end of the path the remaining sweets are handed out and disproportionately many people are waiting there accordingly, is a generic feature of carnival parades. For example, with a length of $10 \mathrm{~km}$, the pageant in Cologne has to be properly disbanded, as experience has shown that this is responsible for persistent congestion on the parade's route.

Table 2: Duration of each procession presented in this contribution calculated for sections at the start the end of the pathway. The parade in Cologne shows a remarkable change of the procession's duration. The duration of the Marksmen's parade in Hanover does not change plainly, whereas in the case of the parade in Duisburg-Hamborn, an increase of the duration is observed.

\begin{tabular}{|c|l|r|r|r|}
\hline \multicolumn{2}{|c|}{} & $\begin{array}{c}\text { Cologne Rose } \\
\text { Monday parade } \\
\mathbf{2 0 1 4}\end{array}$ & $\begin{array}{c}\text { Marksmen's parade } \\
\text { Hanover 2017 }\end{array}$ & $\begin{array}{c}\text { Niederrheinischer } \\
\text { Kinderkarnevalszug 2018 }\end{array}$ \\
\hline $\begin{array}{c}\text { Duration } \\
\text { of } \\
\text { procession }\end{array}$ & Start & $5 \mathrm{~h} 06 \mathrm{~min}$ & $1 \mathrm{~h} 29 \mathrm{~min}$ & $0 \mathrm{~h} 18 \mathrm{~min}$ \\
\cline { 2 - 5 } & End & $4 \mathrm{~h} 10 \mathrm{~min}$ & $1 \mathrm{~h} 23 \mathrm{~min}$ & $0 \mathrm{~h} 24 \mathrm{~min}$ \\
\hline \multicolumn{2}{|c|}{ Relative Contraction } & $22.4 \%$ & $7.2 \%$ & $-33.3 \%$ \\
\hline
\end{tabular}

\section{Conclusion}

In this contribution, we presented a GPS-data-based kinematic analysis of different processions. We analysed the influence of the pathway on the kinematics of the Cologne Rose Monday procession. A number of sections can be identified as flow-reducing bottlenecks. The observed obstructions can be assumed generic for the procession types described here. We further outlined general aspects of processions and executed the data analysis in this context. It is shown that in the case of the Marksmen's parade in Hanover the behaviour of the participants influences the kinematics of the whole procession significantly. Kinematical differences are observed that partially depend on the parade-length/pathway-length ratio and partially on the individual composition of the parades. Although the Marksmen's parade is longer than its pathway, no considerable increase in velocity is observed after the parade leader has left the route. The average velocity of the parade in Duisburg, whose length is smaller than the pathway, shows a decrease. The analysis of the processions presented here prompts that different behavioral patterns of participants can be presumed in processions. It would be interesting to have a systematic study of the rules according to which groups of people move in a regular procession. This would further improve the understanding of the movement of processions.

\section{Acknowledgements}

We would like to thank the Festkomitee Kölner Karneval 1823 e.V. for providing the GPS data of the Cologne Rose Monday parade, as well as the many discussions contributing significantly to the development of this work. Furthermore, we are very grateful to the event management of the city Hanover, in particular Mr. Ralf Sonnenberg, who let us put our GPS devices on the Marksmen's parade. Finally, yet importantly, we would like to thank the parade chief of the Niederrheinischer Kinderkarnevalszug, 
Karlheinz Müller and his associated carnival society 1. Große Karnevalsgesellschaft Rot-Weiß HambornMarxloh for their kind cooperation.

\section{References}

[1] M. Batty, J. Desyllas, and E. Duxbury, "The discrete dynamics of small-scale spatial events: agentbased models of mobility in carnivals and street parades," Int. J. Geographic. Inf. Sci., vol. 17, no. 7, pp. 673-697, 2003.

[2] P. Polichronidis, D. Wegerle, A. Dieper, and M. Schreckenberg, "Traffic dynamics of carnival processions," EPL (Europhysics Letters), vol. 121, no. 6, 2018.

[3] L. Wang, P. D. Groves, and M. K. Ziebart, "Multi-Constellation GNSS Performance Evaluation for Urban Canyons Using Large Virtual Reality City Models," Journal of Navigation, vol. 65, no. 3, pp. 459-476, 2012.

[4] C. A. Scott and C. R. Drane, "Increased accuracy of motor vehicle position estimation by utilising map data: vehicle dynamics, and other information sources" in Vehicle Navigation and Information Systems Conference, Yokohama, Japan, 1994, pp. 585-590.

[5] Festkomitee des Kölner Karnevals von 1823 e.V. (2018, May 10). Rosenmontagszug [Online]. Available: https://koelnerkarneval.de/zuege/\#zug-in-zahlen 